\title{
Clarion and Crystal-Clear Cell Acanthoma Reviewed
}

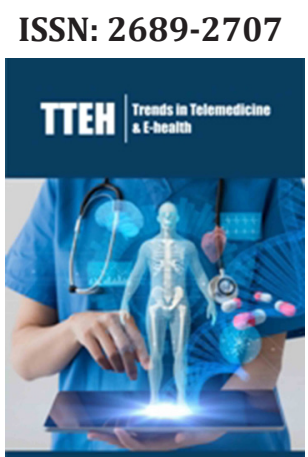

*Corresponding author: Anubha Bajaj, Histopathologist, India

Submission: 侐 June 06, 2019

Published: 鰃July 17, 2019

Volume 1 - Issue 4

How to cite this article: Anubha Bajaj. Clarion and Crystal-Clear Cell Acanthoma Reviewed. Trends Telemed E-Health. 1(4). TTEH. 000520. 2019. DOI: 10.31031/TTEH.2019.01.000520

Copyright@ Anubha Bajaj, This article is distributed under the terms of the Creative Commons Attribution 4.0 International License, which permits unrestricted use and redistribution provided that the original author and source are credited.

\author{
Anubha Bajaj* \\ Department of Pathology, India
}

\begin{abstract}
Clear cell acanthoma or Degos' acanthoma or pale cell acanthoma is an exceptional, asymptomatic, cutaneous benign tumefaction of obscure etiology, emerging from epidermal keratinocytes. Solitary or multiple dome shaped lesions or well delineated nodules or plaques are frequently cogitated on distal extremities. Typically, clear cell acanthoma exhibits a "stuck on" appearance akin to seborrheic keratosis, "vascular countenance" of pyogenic granuloma, "scaling and exudation" elucidated in eczematous reactions and a "progressive margin "associated with an epithelioma. Clear cell acanthoma depicts uniform, pale keratinocytes or pale epithelial cells with abundant cytoplasm composed of excessive glycogen, centric nuclei and distinct foci of transformation. Clinical segregation is required from dermatofibroma, pyogenic granuloma, irritated seborrheic keratosis, keratoacanthoma, actinic keratosis, plaque psoriasis, eccrine poroma, viral warts or malignant cutaneous tumors such as basal cell carcinoma, squamous cell carcinoma, malignant melanoma and metastatic cancer. Dermatoscopy demonstrates a variegated reddish or purple lesion demonstrating a serpiginous pattern akin to a "string of pearls". Comprehensive surgical eradication of the lesion is the recommended therapeutic option.
\end{abstract}

Keywords: Metastatic cancer; Serpiginous; Acanthoma; Inflammation; Tumor

\section{Introduction}

Clear cell acanthoma was portrayed primarily by Degos [1]. Clear cell acanthoma is also referred to as Degos' acanthoma or pale cell acanthoma and is cogitated as an asymptomatic, benign epidermal tumor devoid of gender predilection. Clear cell acanthoma defines a distinct entity on clinical and histological evaluation. Of obscure etiology, the disorder is possibly engendered by inflammation. Apart from exemplifying a benign epidermal tumor, it can be contemplated as a reactive inflammatory dermatosis. Definitive diagnosis of clear cell acanthoma can be challenging as the lesions simulate several benign and malignant skin conditions. Traumatic or drug induced genesis of the neoplasm lacks approval and the disease is of an essentially unknown pathogenesis $[1,2]$.

\section{Disease Characteristics}

An exceptional, cutaneous tumefaction emerging from epidermal keratinocytes is delineated as clear cell acanthoma. Although discerned in younger individuals, the benign neoplasm is frequent in elderly and middle-aged subjects beyond 40 years of age. Gender prevalence is equivalent at M: F: 1:1. Clear cell acanthoma demonstrates solitary or multiple, dome shaped lesions frequently arising on distal extremities. Lesions commonly appear as well delineated nodules or plaques of one to two-centimeter magnitude. Enhanced prevalence of clear cell acanthoma in lower extremities of elderly subjects is of a reactive category probably engendered by "stasis dermatitis". Clear cell acanthoma can be concurrent with modifications akin to syringofibroadenoma, thereby indicating a common derivation from the eccrine apparatus [2,3]. Eruptive variant of clear cell acanthoma depicts spontaneous retrogression with therapy. However, clear cell acanthoma is predisposed to gradual progression.

\section{Clinical Elucidation}

Typically, solitary, miniature, sharply demarcated, firm, non-friable, shiny, erythematous, reddish or orange- brown nodules, papules or an elevated skin lesion with moist, erosive extraneous layer are enunciated with dimensions ranging from 3 millimeters to 20 millimeters. Additionally, a strawberry like reddish purple plaque with a typical psoriasiform appearance and an encompassing fine collarette beneath $<5$-centimeter diameter can be elucidated. Traditionally, clear cell acanthoma exhibits a "stuck on" appearance akin to seborrheic keratosis, "vascular countenance" of pyogenic granuloma, "scaling and exudation" elucidated 
in eczematous reactions and a "progressive margin "associated with an epithelioma. Generally, lower limbs are implicated, although lesions can appear on aberrant, adjunctive sites such as the abdomen, inguinal region, face, thigh, forearm, trunk, scrotum, vermilion mucosa, scalp, palm, nipple and hallux. Lesions blanche upon intense pressure. Pain is infrequent. A discoid, attenuated, marginal crust is often delineated within the lesions of clear cell acanthoma $[3,4]$.

Clinical variants of clear cell acanthoma include the pigmented type, polypoid type, pedunculated type, giant clear cell acanthoma, cystic clear cell acanthoma, eruptive clear cell acanthoma or atypical clear cell acanthoma. Giant clear cell acanthoma depicts lesions ranging betwixt 40 millimeters to 60 millimeters or exceeding 5 centimeters and emerges on the feet, hips or perineum. Giant clear cell acanthoma is thus categorized with appropriate histology. Clinical attributes are variable and recapitulate several lesions such as Bowen's disease, squamous cell carcinoma, malignant melanoma, Kaposi's sarcoma or angiosarcoma. Polypoid variant of clear cell acanthoma was essentially discovered by Petzelbauer and Konrad in 1990. Lesion appear amidst 4 millimeters to 30 millimeters in dimension and are situated on the femur, lower extremities, neck, scalp or nipple. Pigmented clear cell acanthoma was initially discerned by Fanti et al in 1990. Melanocytes and melanin pigment are detected on histological assessment within the clear cells and contribute to the emergence of a brownish discoloration $[4,5]$. Eruptive variant of clear cell acanthoma demonstrates lesions betwixt 1 centimeter to 10 -centimeter diameter and majority are situated on lower extremities although upper limbs can be incriminated. Atypical variant of clear cell acanthoma or benign clear cell acanthoma can undergo malignant change. Squamous cell carcinoma in situ can arise in clear cell acanthoma. Cystic variant of clear cell acanthoma demonstrates the presence of hair follicles. Supra-pubic and abdominal lesions are elucidated.

\section{Histological Elucidation}

Characteristic histological attributes of clear cell acanthoma includes abundant representative clear cells or cells with transparent cytoplasm, typically confined to the epidermis. Clear cells abound in glycogen and are reactive to periodic acid Schiff's (PAS) stain, labile with diastase. Occasionally, clear cells are absent, and cells can be non-reactive to periodic acid Schiff (PAS) stain. Lateral margin of the lesions is sharply defined and well demarcated. On microscopy, lesions are constituted of uniform, pale keratinocytes or pale epithelial cells and demonstrate distinct foci of transformation from adjacent normal, uninvolved superficial epidermis. Keratinocytes enunciate abundant quantities of pale staining cytoplasm and centric nuclei $[5,6]$. Keratinocytes appear as palely stained cells on account of excessive amounts of incorporated glycogen and are delineated distinctly with periodic acid Schiff's (PAS) stain which can be eliminated with diastase that assimilates the glycogen.

Clear cells are especially enunciated within the epidermis except the basal layer. Granular epidermal cell layer is absent, and the lesions are devoid of melanin. Supra-papillary epidermal plate is attenuated except the within the region of adnexal epithelium. Clear cell acanthoma is composed of squamous epithelium where the superficial epidermis demonstrates acanthosis with psoriasiform epithelial hyperplasia accompanied by amalgamation of adjacent rete ridges. Dermis, predominantly papillary dermis, displays a diffuse inflammatory infiltrate composed of neutrophils accompanied by distended, enlarged vasculature. Additionally, aggregates of intra-lesioned neutrophils are classically exemplified within the superimposed parakeratotic epithelial crust $[6,7]$. Lesions of clear cell acanthoma manifesting aforesaid epithelial modifications are sharply defined and segregated from abutting, uninvolved squamous epithelium Histological description of clinical variants of clear cell acanthoma necessitate the demonstration of classic, pale staining, minimally enlarged epithelial cells confined to the epidermis, the elucidation of which is mandatory for definitive diagnosis of clear cell acanthoma.

\section{Differential Diagnosis}

Segregation of clinical lesions of clear cell acanthoma is mandated from dermatofibroma, pyogenic granuloma, irritated seborrheic keratosis, keratoacanthoma, actinic keratosis, plaque psoriasis, eccrine poroma, viral warts or malignant cutaneous tumors such as basal cell carcinoma, squamous cell carcinoma, malignant melanoma and metastatic cancer. On extraneous examination, lesions simulate those of psoriasis, lichen planus and discoid lupus erythematosus $[7,8]$. Demarcation is required from psoriasis vulgaris. Lesions depict a distinct transformation betwixt the normal, uninvolved epidermis and epidermal accumulations of clear, pale cells, although clear cell aggregates can be absent. Distinction from trichilemmoma is necessitated. Lesions are devoid of neutrophils. Cellular aggregates are circumscribed by dense, eosinophilic basement membrane material and display a peripheral palisade. Several squamous eddies can be cogitated.

\section{Investigative Profile}

Pertinent dermatoscopy can augment diagnostic precision. Dermatoscopic pattern of clear cell acanthoma was appropriately elucidated by Blum in 2001. Clear cell acanthoma exemplifies singularly unique attributes on dermatoscopy which depicts a variegated reddish or purple lesion demonstrating a serpiginous pattern akin to a "string of pearls". Characteristic red dots, globules and coiled (glomerular-like) vasculature is configured in a serpiginous manner. Augmentation of serpiginous articulations are prominently symmetric. Occasionally the vascular arrangement in incomplete or partially evolved with the emergence of "forme fruste" or a compression artefact. Discoloration due to melanin (black, brown, gray, blue) is not evident in the lesions. Lesions are described as symmetrical, partially homogeneous or cogitating a bunch-like configuration with pinpoint capillaries. Lesions of clear cell acanthoma are, nevertheless, distinct $[8,9]$. Dot or coiled (glomerular-like) blood vessels are characteristic of reactive inflammatory dermatosis such as psoriasis, pityriasis lichenoid and discoid eczema. However, red dots and coiled vasculature are uniformly disseminated and do not amalgamate to configure a serpiginous, vascular arrangement. Infrequent dermatoscopic 
features of clear cell acanthoma include areas of hemorrhage, orange- tinted superficial keratinous incrustation and a collarette of translucent scales appearing on the periphery. Application of polarized dermatoscopy in evaluating clear cell acanthoma depicts the emergence of numerous crystalline structures $[8,9]$.

\section{Therapeutic Options}

As clear cell acanthoma is a benign epidermal tumor and demonstrates a classic serpiginous vascular configuration, therapeutic surgical eradication is unnecessary in miniature, asymptomatic lesions. As it can be challenging to ascertain the nature of the lesion as benign or malignant, comprehensive surgical eradication is the recommended therapeutic option $[9,10]$. Cogent therapeutic strategies are pertinent to the magnitude, site and quantification of lesions as well as personal preference of the treating surgeon. Surgical extermination is optimal for solitary lesions. Additional therapeutic modalities include Moh's microsurgery, curettage, electro-fulguration, cryotherapy and carbon dioxide $\left(\mathrm{CO}_{2}\right)$ laser. Cryosurgery is beneficial in the management of multiple lesions. Benign clear cell adenoma is contemplated to be cured following a comprehensive surgical elimination which incorporates the sharply defined lateral contours. Exceptionally, reoccurrences can occur following adequate surgical excision (Figure 1-12); [1120]. A tumor free surgical perimeter of 3 millimeters can be adopted as a pertinent therapeutic preference. Follow up can demonstrate an absence of reoccurrence of the lesion. However, close monitoring is necessitated on account of potential malignant conversion.

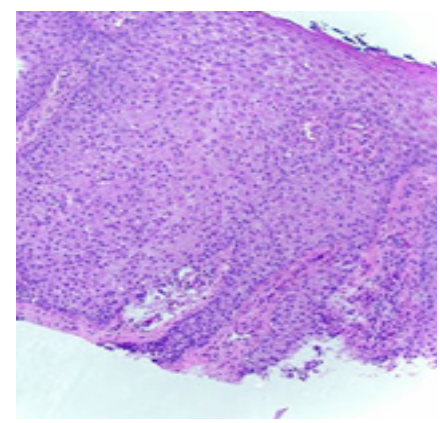

Figure 1: Sharply defined clear cell aggregates with fused rete ridges in clear cell acanthoma [11].

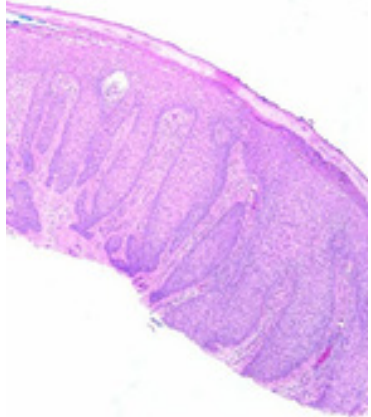

Figure 2: Hyperkeratosis, parakeratotic crust, dermal inflammation and adherent rete ridges in clear cell acanthoma [11].

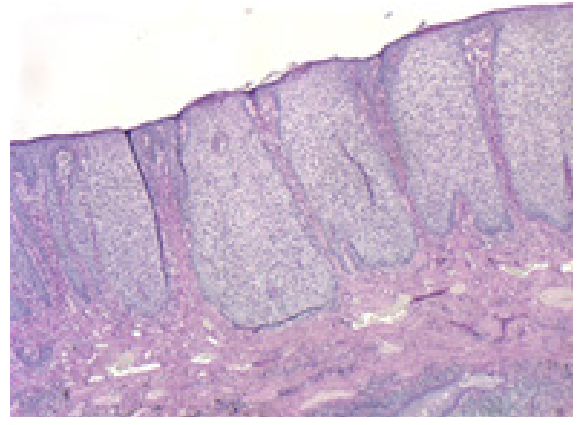

Figure 3: Aggregates of clear cells with glycogen accumulation and dermal inflammatory egress in clear cell acanthoma [12].

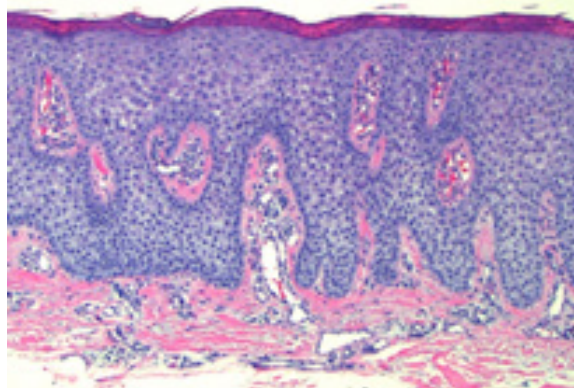

Figure 4: Amalgamated rete ridges, clear cell nests and superimposed parakeratosis in clear cell acanthoma [13].

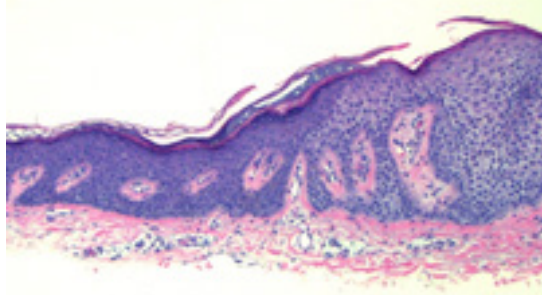

Figure 5: Rete ridges fusion, parakeratotic crusting and epidermal accumulations of glycogen enriched clear cells in clear cell acanthoma [13].

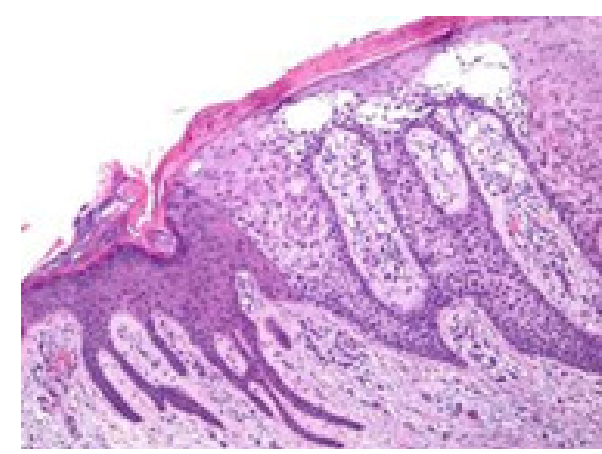

Figure 6: Elongated, fused rete ridges, dermal lymphocytes, clear cell nests and hyperkeratosis in clear cell acanthoma [14]. 


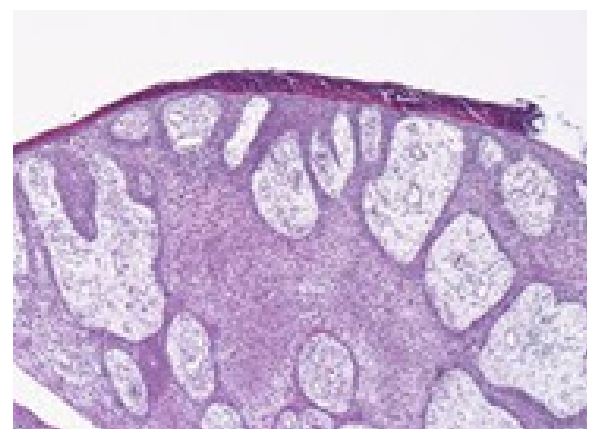

Figure 7: CCA Angio- eccrine hyperplasia, adherent rete ridges, clear cell masses and parakeratosis in clear cell acanthoma [15].

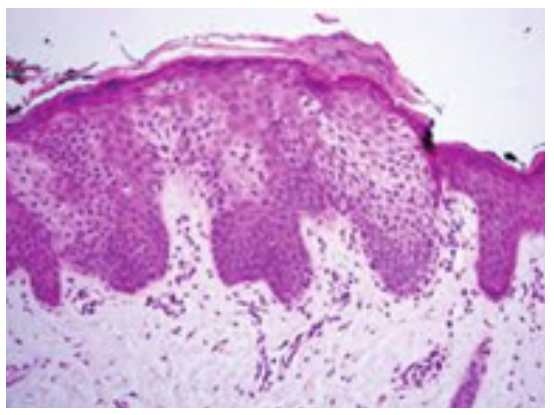

Figure 8: Clear cell aggregates and parakeratotic flakes in clear cell acanthoma [16].

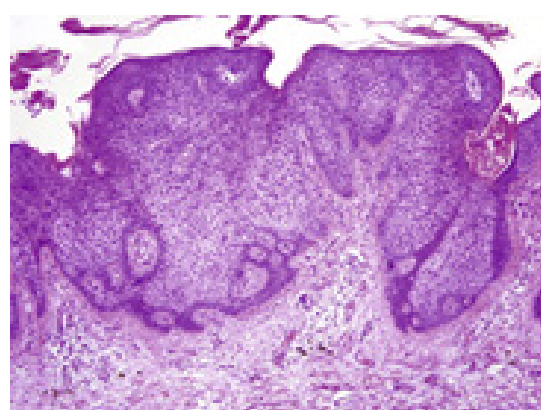

Figure 9: Adjoining rete ridges, lobules of clear cells and parakeratotic scales in clear cell acanthoma [17].

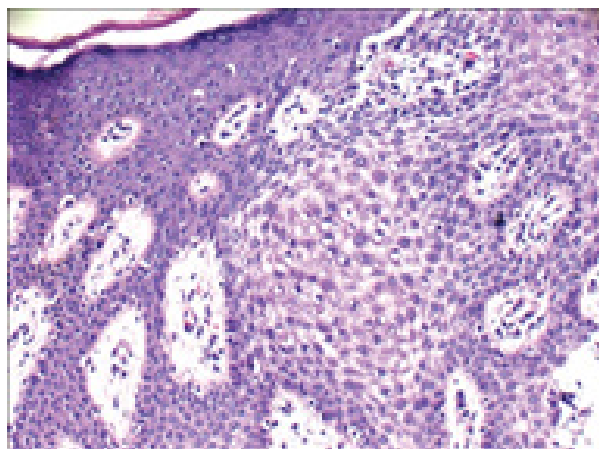

Figure 10: Glycogen imbued clear cells with fused rete ridges and hyperkeratosis in clear cell acanthoma [18].

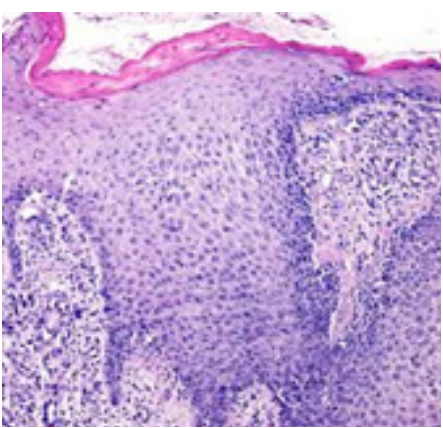

Figure 11: Hyperkeratosis, clear cell lobulation and dermal inflammatory infiltrate in clear cell acanthoma [19].

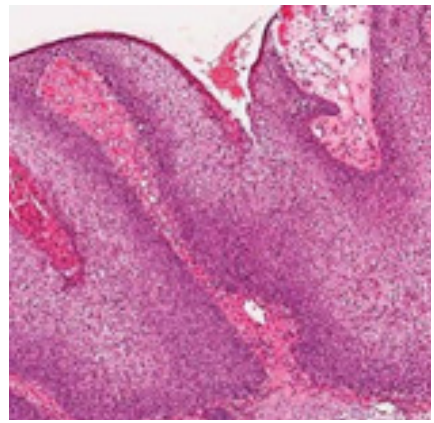

Figure 12: Malignant conversion of clear cell acanthoma with cellular atypia and mitosis within the clear cell nests [20].

\section{References}

1. Degos R, Delort J, Civatte J, Poiares BA (1962) Epidermal tumor with an unusual appearance-clear cell acanthoma. Ann Dermatol Syphiligr (Paris) 89: 361-371.

2. Brownstein MH, Fernando S, Shapiro L (1973) Clear cell acanthoma: Clinicopathologic analysis of 37 new case. Am J Clin Pathol 59(3): 306311.

3. Bubna AK, Joseph LD, Mahalakshmi V, Sudha R (2014) Degos like non clear cell acanthoma: Could this be a new entity? Indian J Clin Pract 25(7): 640-642.

4. Eyuboglu AA, Togral AK, Eda YA, Nilgün ME (2018) Clear cell acanthoma in an unexpected location. Turk J Plast Surg 26(1): 40-42.

5. Zargari O, Azimi SZ, Geranmayeh S (2018) Giant clear cell acanthoma with dermatoscopic white lines. Drmatol Pract Concept 8(3): 245-247.

6. Park SY, Jung JY, Na JI, Byun HJ, Cho KH (2010) A case of polypoid clear cell acanthoma on the nipple. Ann Dermatol 22(3): 337-340.

7. Arida M, English JC, Mully TW (2006) Giant clear cell acanthoma with keratoacanthoma like changes: A case report. Dermatol Online J 12(4): 11.

8. Roytman M, Frumkin A, Mark AE (1987) Giant clear cell acanthoma. Am Acad Dermatol 17(3): 513-514.

9. Kim CY, Kim NG, Oh CW (2010) Multiple reddish weeping nodules in the genital area of a girl: Giant clear cell acanthoma. Clin Exp Dermatol 35(3): e67-e69.

10. Garcia GJ, Gonzalez VD, Montero I, Rodríguez PL, Pereiro MM, et al. (2011) Disseminated eruptive clear cell acanthoma with spontaneous regression-further evidence of an inflammatory origin. Am J Dermatopathol 33(6): 599-602. 
11. Image 1 and 2 Courtesy: Pathology Outlines

12. Image 3 Courtesy: eScholarship.com

13. Image 4 and 5 Courtesy: Dermpath daily

14. Image 6 Courtesy: aocd.com

15. Image 7 Courtesy: J Am Acad Dermatol
16. Image 8 Courtesy: Wiley online library

17. Image 9 Courtesy: Science direct

18. Image 10 Courtesy: Turkish J Plastic Surgery

19. Image 11 Courtesy: Research gate

20. Image 12 Courtesy: Semantic scholar

For possible submissions Click below: 